Scientific Review - Engineering and Environmental Sciences (2017), 26 (3), 317-325

Sci. Rev. Eng. Env. Sci. (2017), 26 (3)

Przegląd Naukowy - Inżynieria i Kształtowanie Środowiska (2017), 26 (3), 317-325

Prz. Nauk. Inż. Kszt. Środ. (2017), 26 (3)

http://iks.pn.sggw.pl

DOI 10.22630/PNIKS.2017.26.3.31

\author{
Mohsen REZAEI ${ }^{1}$, Mohammad GHAFOORI ${ }^{1}$, Rasoul AJALLOEIAN ${ }^{2}$ \\ ${ }^{1}$ Ferdowsi University of Mashhad, Iran \\ ${ }^{2}$ University of Isfahan, Iran
}

\title{
Comparison between deformation modulus of rock mass measured by plate jacking and dilatometer tests
}

Key words: plate jacking test, dilatometer test, deformation modulus, Bakhtiari Dam, geotechnics

\section{Introduction}

The deformation modulus of rock mass $\left(E_{r m}\right)$ is an important input parameter for many rock engineering projects, including tunneling, support design, foundation design, etc. It defines the relationship between applied stress and resulting deformations (including elastic and inelastic behavior) that describes pre-failure mechanical behavior of rocks.

Rock mass deformation modulus can be determined by in-situ tests, such as: plate loading, plate jacking (PJT), radial jacking, flat jack, cable jack, and dilatometer (DLT) (Galera, Alvarez \& Bieniawski, 2007; Isik, Doyuran \& Ulusay, 2008; Kavur, Stambuk Cvitanović \& Hrženjak, 2015). These tests are time-consuming, expensive, and difficult to conduct and the reliability of the results is sometimes questionable (Palmstrom \& Singh, 2001; Hoek \& Diederichs, 2006). Besides, in-situ test results may be very different depending on the test method (Agharazi, Tannant \& Derek Martin, 2012; Kavur et al., 2015). This means that relying on just one in-situ method is difficult. So, to cross check the results, two or more types of tests should be used (Aliasghari \& Ahadi, 2007). Unfortunately, few projects have a sufficient number of different in-situ tests to allow a meaningful comparison of data. The PJTs and DLTs are the most common in-situ tests performed in major projects to determine $E_{r m}$. In this paper, the values of $E_{r m}$ measured by PJTs and DLTs were compared at Bakhtiari Dam site. The Bakhtiari Dam site is located in the south-west of Iran, almost $70 \mathrm{~km}$ north-east of Andimeshk town (Khuzestan province) and $65 \mathrm{~km}$ south-west of Dorud town (Lorestan province). 


\section{Geotechnical investigations}

The rock masses at the Bakhtiari Dam site belong to Sarvak formation. The Sarvak formation in the study area has been divided into seven units namely Sv1 to Sv7. The units Sv2 to Sv6 have outcrops on the dam site. Unit Sv2 consists of marly limestone with thin inter-bedding of marl and shale. Unit Sv3 consists of an intercalation of marl and siliceous limestone. Some parts of unit Sv3 are folded and heterogeneous named as kink band zone (KB). Unit
Sv4 includes of medium to thick bedded limestone with siliceous nodules. Unit Sv 5 consists of thick to very thick bedded nodular limestone. Unit Sv6 is made of thick bedded and marl limestone with thin marl intercalations. Geotechnical investigations of the Bakhtiari Dam site include joint study, drilling of boreholes, performing laboratory tests, excavating exploratory galleries, and performing in-situ deformability tests. The location of in-situ tests are shown on the geological map as Figure 1.

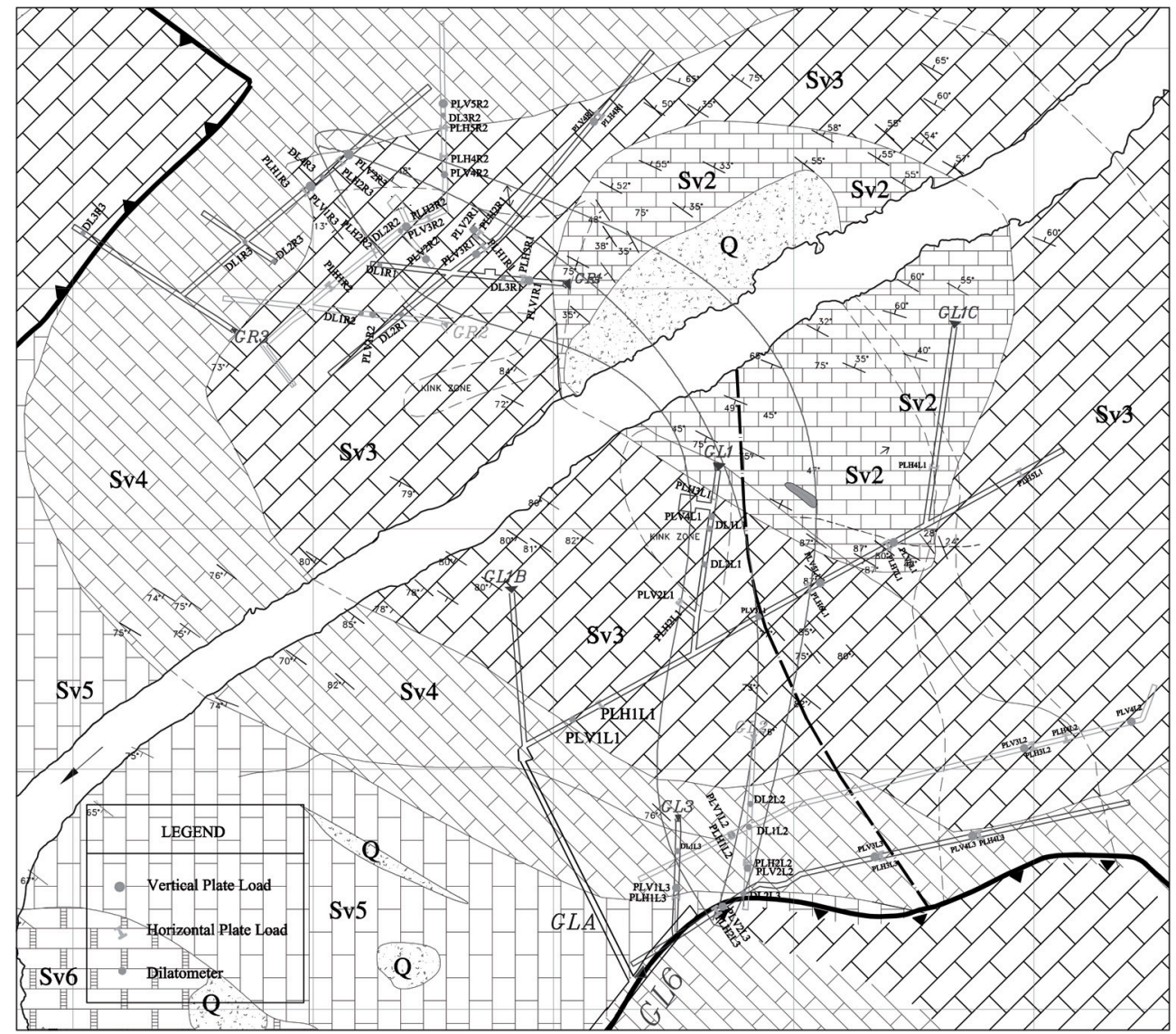

FIGURE 1. Location of in-situ tests in geological map of dam site 


\section{In-situ tests}

To evaluate the $E_{r m}$ at the Bakhtiari Dam site and during geotechnical investigations, from 2004 to 2009, 89 PJTs in vertical and horizontal directions and 83 DLTs that determine the $E_{r m}$ in three directions were performed. As shown in Figure 1, the PJTs and DLTs have been performed in various geological and geotechnical conditions in the most parts of the dam site. The PJTs and DLTs in the same geological and geotechnical conditions were categorized into a group and were compared with each other.

\section{Plate jacking test}

Plate jacking tests (PJTs) were frequently used in rock engineering to determine the deformability of the rock mass. In order to make the test results representative of jointed rock, large loading plates were used to encompass several joints in the rock mass. The PJTs are usually carried out with five loading and unloading cycles (ISRM, 1979).

Plate jacking tests at Bakhtiari Dam site were carried out using rigid loading plates with diameters of 650 and $915 \mathrm{~mm}$. The rock displacements are measured using borehole extensometers fixed at five positions inside boreholes drilled in the center of each loading area. Thus, we have five measuring points behind each loading area for which moduli can be calculated. There is an increasing trend in moduli values with depth depending on rock mass quality. With high quality rock masses, the rate of increasing is very high, but for very low quality rock masses this is insignificant. In the present study, the selected modulus of rock masses for each loading area is an average modulus of two or more points that is chosen by expert judges.

According to ASTM (2008), for a circular rigid plate test, when measurement of displacement is done in a borehole beneath the loading plate, the basic formula for calculating $E_{r m}$ is:

$$
E_{r m}=\frac{(1+v) P}{2 \pi W_{z} R}\left[(2-2 v) \arcsin \left(\frac{R}{\left(R^{2}+Z^{2}\right)^{0.5}}+\frac{R Z}{R^{2}+Z^{2}}\right)\right]
$$

where:

$E_{r m}-$ deformation modulus of rock mass [GPa];

$P$ - total load on the loading plate $(\mathrm{KN})$;

$R$ - radius of loading plate [mm];

$Z$ - depth of measurement point [mm];

$W_{z}$ - displacement in each depth [mm];

$v$ - Poisson's ratio of rock mass.

The Poisson's ratio of rock mass considered 0.3 for all the rock masses due to the insignificant effect of $v$ within the interval of $0.1-0.35$ on the deformation modulus of rock masses (Palmstrom \& Singh, 2001).

From all PJTs, about $47 \%$ were performed horizontally and 53\% vertically. Comparison between vertical and horizontal test results shows insignificant differences (Table 1, Fig. 2).

TABLE 1. Comparison between horizontal and vertical PJTs by t-test

\begin{tabular}{|l|c|c|}
\hline Parameter & Horizontal & Vertical \\
\hline Mean & 10.24 & 10.11 \\
\hline Variance & 73.59 & 56.13 \\
\hline Observations & 42 & 47 \\
\hline $\mathrm{t}$-Stat & \multicolumn{2}{|c|}{0.076} \\
\hline$P(T \leq t)$ one-tail & \multicolumn{2}{|c|}{0.47} \\
\hline $\mathrm{t}$-Critical one-tail & \multicolumn{2}{|c|}{1.66} \\
\hline$P(T \leq t)$ two-tail & \multicolumn{2}{|c|}{0.94} \\
\hline $\mathrm{t}$-Critical two-tail & \multicolumn{2}{|c|}{1.99} \\
\hline
\end{tabular}




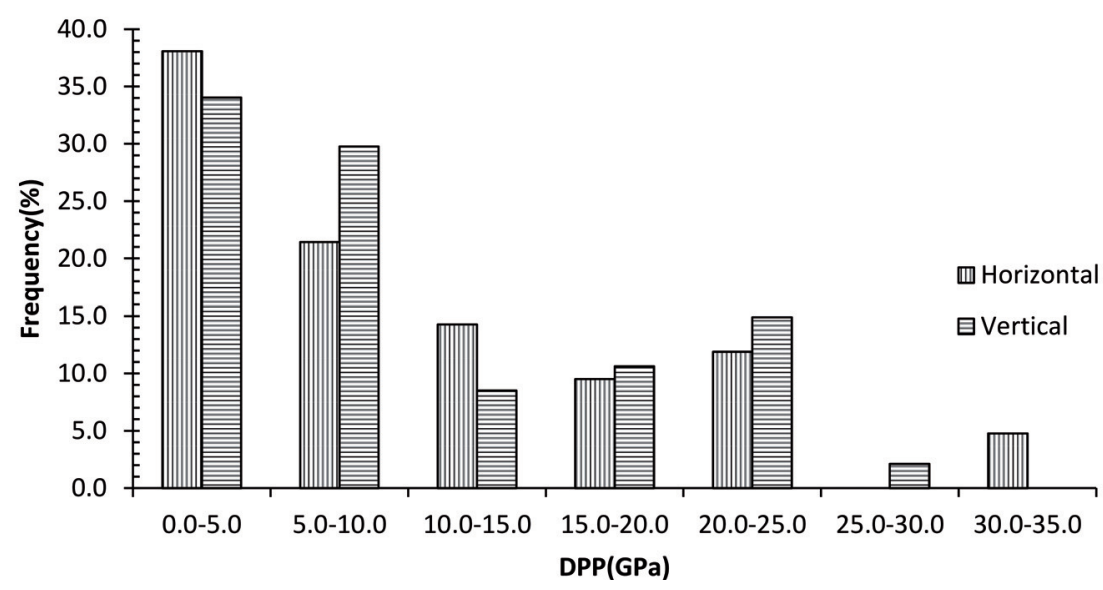

FIGURE 2. Frequency of DPP values measured by PJTs in horizontal and vertical direction

\section{Dilatometer test}

In order to determine the deformation modulus of rock masses, DLTs are carried out in some boreholes. For this purpose, a high pressure flexible membrane with dilatometers of $102 \mathrm{~mm}$ is used with three displacement sensors arranged at $120^{\circ}$ to each other. The loading, which causes the borehole to expand outwards, is applied to the wall of the borehole uniformly by using a rubber sleeve. The displacement transducers are in contact with the rock surface and measure its deformation. Then, the average of measured moduli in three directions is used as deformation modulus of rock mass.

According to ISRM suggested method for deformability determination using a flexible dilatometer with radial displacement measurements (Ladanyi, 1987), the tests are performed in three cycles of loading and unloading with at least five pressure increment and decrement steps in each loading and unloading cycle.
Deformation modulus of rock mass is calculated from the relationship between applied pressure and resulting dilation (ISRM, 1989; USBR, 2009). In rocks with widely spaced joints, the rock mass deformation modulus may be calculated as follows (Ladanyi, 1987):

$E_{d}=\left(1+v_{r m}\right) D \frac{\Delta P_{i}}{\Delta D}$

where:

$E_{d}$ - modulus of deformation [MPa];

$v_{r m}$ - Poisson's ratio of rock mass (considered equal to 0.3 );

$D$ - diameter of borehole [mm];

$\Delta P_{i}$ - pressure increment within the considered segment [MPa];

$\Delta D$ - corresponding average change in borehole diameter [mm].

If the test media is a cracked rock and applied pressure exceeds about twice the average ground pressure around the borehole, all existing radial cracks will be opened and the above equation should be replaced by (Ladanyi, 1987): 
$E_{d}=\left(1+v_{r m}\right) D \frac{\Delta P_{i}}{\Delta D}\left[\left(1-v_{R}\right) \ln \left(\frac{P_{i}}{2 P_{0}}\right)+1\right]$

(3)

where:

$P_{i}$ - applied pressure [MPa];

$P_{0}$ - average ground pressure [MPa].

Because of anisotropy of rock masses, the deformation modulus of rock mass may vary in different directions. The histogram of measured modulus in three directions is presented in Fig- ure 3. In the Bakhtiari Dam site, anisotropy of rock masses in different locations is not in the same direction. For example, as seen in Figure 4, the performed tests in different depths of borehole DL1L5 show the highest deformation modulus in different directions. Evaluation of deformation modulus of rock mass in different directions in the DLTs all over the Bakhtiari Dam site shows insignificant differences between deformation moduli in three directions (Table 2).

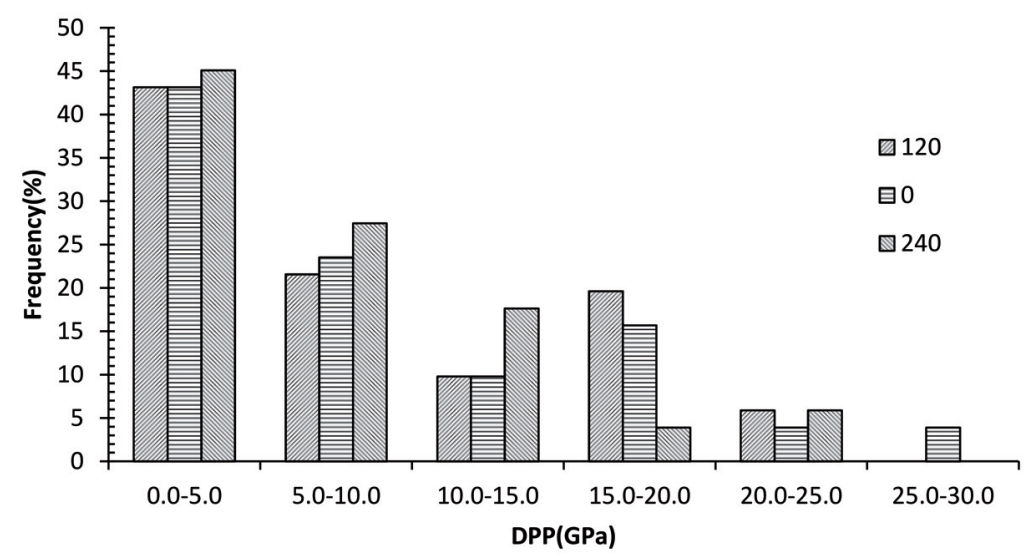

FIGURE 3. Frequency of DPP value in three directions in DLTs

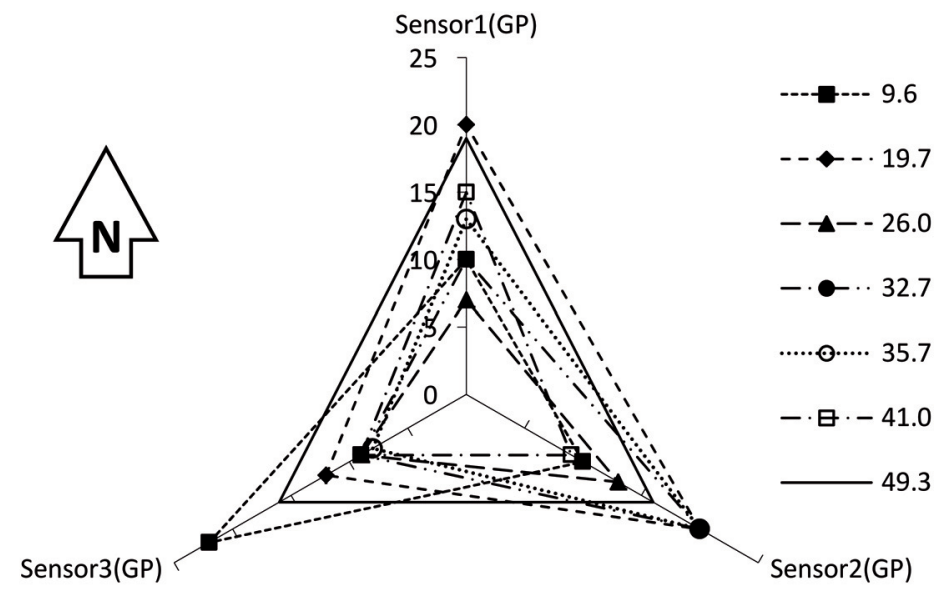

FIGURE 4. Measured DPP in different depths of DL1L5 borehole in three direction 
TABLE 2. Comparison between DPP of DLTs in different directions

\begin{tabular}{|l|c|c|}
\hline Correlation between & $0-120^{\circ}$ & $0-240^{\circ}$ \\
\hline Pearson's correlation & 0.69 & 0.55 \\
\hline t-Stat & 0.32 & 1.73 \\
\hline$P(T \leq t)$ one-tail & 0.37 & 0.05 \\
\hline t-Critical one-tail & 1.68 & 1.68 \\
\hline$P(T \leq t)$ two-tail & 0.75 & 0.09 \\
\hline t-Critical two-tail & 2.01 & 2.01 \\
\hline
\end{tabular}

\section{Comparisons between PJT and DLT results}

In this study, the data obtained from these in-situ tests are examined and an incredible database is compiled consequently. Figure 5 shows the histogram of in-situ data and the descriptive analysis of data presented in Table 3. The in-situ tests are performed on six rock units of Sarvak formation at Bakhtiari Dam site. Therefore, the data are divided into six groups. The summary of the results of PJTs and DLTs are presented in Table 4 and Table 5, respectively.
As mentioned above, there are no significant differences between the deformation modulus of rock mass measured by PJTs in vertical and horizontal directions. Also, the differences between DLTs measurements in three directions are insignificant.

Therefore, since the PJTs and DLTs are not carried out in the same location at the dam site to make a meaningful one-to-one comparison between the results of these two methods, and also, due to insignificant differences between test results in different directions, the mean of in-situ data of each rock units and also the overall mean of all data are compared with each other. The results of this correlation are presented in Table 6 and Figure 6. It clearly shows that there is a good relation between dilatometer and PJT results. However, the moduli measured by DLTs are greater than PJTs ones in low quality rock masses. Contrariwise, the moduli measured by PJTs are greater than DLTs ones in high quality rock masses.

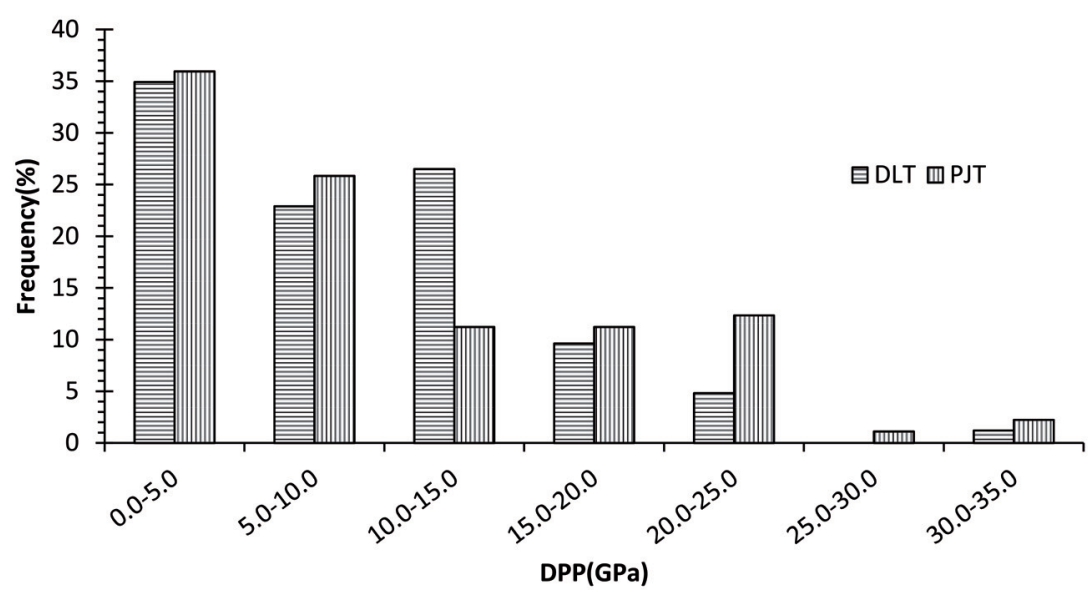

FIGURE 5. Histograms of in-situ tests results 
TABLE 3. Descriptive statistics of in-situ tests data

\begin{tabular}{|l|c|c|}
\hline Parameters & $\begin{array}{c}\text { DLT DPP } \\
{[\mathrm{GPa}]}\end{array}$ & $\begin{array}{c}\text { PJT DPP } \\
{[\mathrm{GPa}]}\end{array}$ \\
\hline Mean & 9.69 & 10.13 \\
\hline Median & 9.00 & 7.40 \\
\hline Mode & 3.00 & 2.40 \\
\hline SD & 6.40 & 7.93 \\
\hline Min & 1.00 & 0.90 \\
\hline Max & 31.00 & 33.10 \\
\hline Count & 83 & 89 \\
\hline
\end{tabular}

tric test used to compare differences between two independent groups when the dependent variable is continuous. The results of Mann-Whitney $U$ test for the DPP is presented in Table 7 and it provides the test statistic, U statistic, as well as the asymptotic significance (two-tailed) p-value. From this table, it can be concluded that the difference of DPP for two types of in-situ tests is insignificant $(p>0.05)$.

TABLE 4. Summary of PJTs results

\begin{tabular}{|l|c|c|c|c|c|c|c|}
\hline Rock unit & Sv2 & Sv3 & Sv3-Kb & Sv4 & Sv5 & Sv6 & All data \\
\hline Count & 6 & 55 & 6 & 10 & 4 & 8 & 89 \\
\hline Mean of DPP [GPa] & 12.3 & 8.7 & 4.2 & 4.6 & 22.4 & 23.7 & 10.1 \\
\hline
\end{tabular}

TABLE 5. Summary of DLTs results

\begin{tabular}{|l|c|c|c|c|c|c|c|}
\hline Rock unit & Sv2 & Sv3 & Sv3-Kb & Sv4 & Sv5 & Sv6 & All data \\
\hline Count & 4 & 21 & 16 & 27 & 7 & 7 & 83 \\
\hline Mean of DPP $[\mathrm{GPa}]$ & 13.0 & 11.5 & 6.7 & 6.6 & 16.6 & 15.1 & 9.7 \\
\hline
\end{tabular}

TABLE 6. The mean of DPP measured by PJT and DLT

\begin{tabular}{|l|c|c|}
\hline \multirow{2}{*}{ Rock unit } & \multicolumn{2}{|c|}{ DPP [GPa] } \\
\cline { 2 - 3 } & DLT & PJT \\
\hline SV2 & 13.0 & 12.3 \\
\hline SV3 & 11.5 & 8.7 \\
\hline SV3-KB & 6.7 & 4.2 \\
\hline SV4 & 6.6 & 4.6 \\
\hline SV5 & 16.6 & 22.4 \\
\hline SV6 & 15.1 & 23.7 \\
\hline All & 9.7 & 10.1 \\
\hline
\end{tabular}

To make a better comparison between PJTs and DLT data, the differences between two groups of in-situ data are compared using Mann-Whitney U test (Mann \& Whitney, 1974). The Mann-Whitney U test is a non-parame-

\section{Conclusions}

The deformation modulus of rock mass is considered as one of the most important parameters for investigating the rock mass behavior. In-situ tests have been considered as the most authentic procedures to evaluate this parameter. Several in-situ tests, such as PJTs and DLTs, were carried out to obtain $E_{r m}$ during geotechnical investigation of the Bakhtiari Dam site. Statistical analyses were performed for comparison between PJT and DLT results. Due to the lack of paired data from PJTs and DLTs to make a meaningful one-to-one comparison, the mean of in-situ data of each rock unit and also the overall mean of all data were compared with each other. 


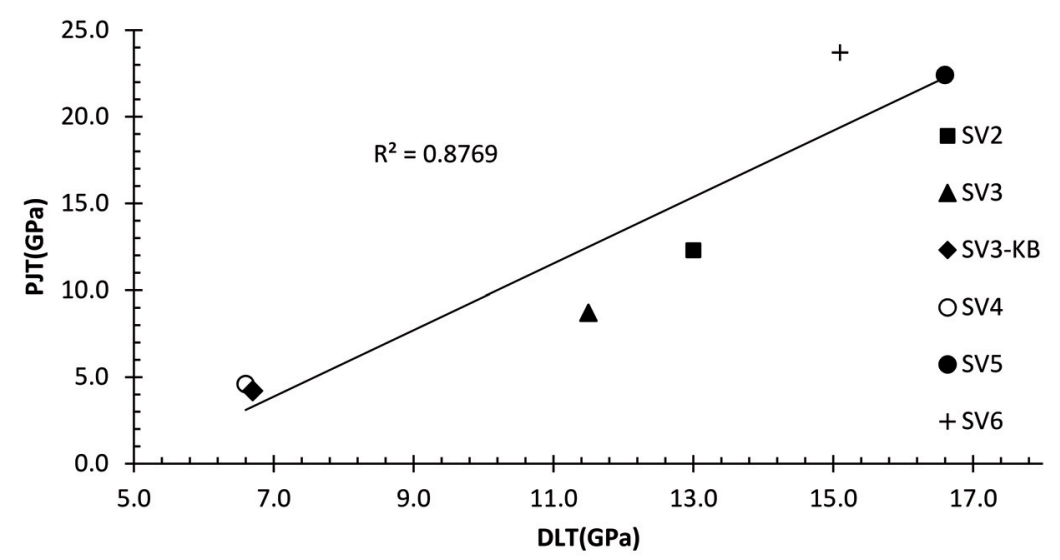

FIGURE 6. The mean values of DPP for DLTs versus PJTs

TABLE 7. Mann-Whitney U test statistics table

\begin{tabular}{|l|c|}
\hline Mann-Whitney U & 3634 \\
\hline Wilcoxon W & 7639 \\
\hline Z & -0.18 \\
\hline $\begin{array}{l}\text { Asymptotic significance } \\
\text { (two-tailed) }\end{array}$ & 0.85 \\
\hline Exact significance (two-tailed) & 0.86 \\
\hline
\end{tabular}

The comparisons have shown that there were no significant differences between mean of these in-situ data, but the results of DLTs were greater than the PJTs in low quality rock masses. Contrariwise, in high quality rock masses, the results of PJTs were greater than the DLTs.

Due to stress relief and excavation damages disturbance in shallow rock mass and also very low displacement in deeper rock mass, the moduli obtained from PJTs at shallow extensometer locations are usually smaller than the deeper ones. Therefore, correlating PJT and DLT results can lead to a selection of acceptable data. In the high quality rock masses, the average of extensometer measurements of first $50 \mathrm{~cm}$ thick of rock mass could be used to estimate the $E_{r m}$ whereas, in weak rock masses, the deeper extensometer measurements can be used too.

\section{References}

Agharazi, A., Tannant, D.D. \& Derek Martin, C. (2012). Characterizing rock mass deformation mechanisms during plate load tests at the Bakhtiary dam project. International Journal of Rock Mechanics and Mining Sciences, 49, 1-11. 10.1016/j.ijrmms.2011.10.002.

Aliasghari, H. \& Ahadi, B. (2007). Effect of Anisotropy on Rock Mass Deformation Modulus in Javeh Dam Site. Proceedings of 11th ACUUS Conference: Underground Space: Expanding the Frontiers. Athens, Greece, 469-473.

ASTM (2008). Standard Test Method for Determining the in Situ Modulus of Deformation of Rock Mass Using the Rigid Plate Loading Method. D 4394-08.

Galera, J.M., Alvarez, M. \& Bieniawski, Z.T. (2007). Evaluation of the deformation modulus of rock masses using RMR Comparison with dilatometer tests, Underground Works under Special Conditions: Madrid.

Hoek, E. \& Diederichs, M.S. (2006). Empirical estimation of rock mass modulus. International Journal of Rock Mechanics and Mining Sciences, 43, 203-215. 
Isik, N.S., Doyuran, V. \& Ulusay, R. (2008). Assessment of deformation modulus of weak rock masses from pressuremeter tests and seismic surveys. Bulletin of Engineering Geology and Environment, 6, 293-304. 10.1007/s10064-008-0163-0.

ISRM (1979). Suggested methods for determining in-situ deformability of rock- Part I: Suggested method for deformability determination using a plate test. International Journal of Rock Mechanics Mining Sciences and Geomechanics, 16, 197-202.

ISRM (1989). ISRM suggested method, rock characterization, testing and monitoring. London: Pergamon.

Kavur, B., Štambuk Cvitanović, N. \& Hrženjak, P. (2015). Comparison between plate jacking and large flat jack test results of rock mass deformation modulus. International Journal of Rock Mechanics and Mining Sciences, 73, 102-114. 10.1016/j.ijrmms.

Ladanyi, B. (1987). ISRM Testing Methods - Suggested Methods for Deformability Determination Using a Flexible Dilatometer. International Journal of Rock Mechanics Mining Sciences and Geomechanics, 24(2), 123-134.

Mann, H.B. \& Whitney, D.R. (1974). On a test of whether one of two random variables is stochastically larger than the other. Annals of Mathematical Statistics, 18(1), 50-60. 10.1214/aoms/1177730491.

Palmstrom, A. \& Singh, R. (2001). The deformation modulus of rock masses - comparisons between in situ tests and indirect estimates. Tunnelling and Underground Space Technology, 16(3), 115-131.

USBR (2009). Determining Situ Deformation Modulus Using a Flexible Volumetric Dilatometer. 6575-09.

\section{Summary}

Comparison between deformation modulus of rock mass measured by plate jacking and dilatometer tests. For determination of the in-situ deformation modulus of rock mass at Bakhtiari Dam site, located in south-west of Iran, plate jacking tests (PJT) and dilatometer tests (DLT) carried out during the geotechnical investigations. In this study, the results of PJTs and DLTs were compared. This comparison involves 89 vertical and horizontal PJTs and 83 DLTs carried out in 6 rock units of Sarvak formation. Although, both PJTs and DLTs in the Bakhtiari Dam site were performed in same geological and geotechnical conditions, but there are not sufficient side by side data to make a paired two samples correlation. Therefore, the mean of in-situ data was compared at each rock unit. Besides Mann-Whitney U tests were performed to compare in-situ test results. The comparison shows that the deformation modulus measured by both methods has no significant differences. However, in low quality rock masses the moduli measured by the use of DLTs were greater than the modulus measured by PJTs. Conversely, in high quality rock masses the results of PJTs were greater than DLT's.

\section{Authors' address:}

Mohsen Rezaei, Mohammad Ghafoori Ferdowsi University of Mashhad 9177948974 Azadi Square, Mashhad Iran e-mail: Ghafoori@um.ac.ir 